\title{
UMA BOTIJA NA SALA DE AULA: LEITURA DE ROMANCE NA EDUCAÇÃO DE JOVENS E ADULTOS
}

\author{
Ananília Meire Estevão da Silva \\ Márcia Tavares
}

\begin{abstract}
Resumo: Neste artigo, após situar uma experiência de leitura com o romance $A$ botija, de Clotilde Tavares, com alunos do EJA, recortamos e refletimos sobre a vivência com o folheto $O$ romance do Pavão Misterioso, de José Camelo de Melo Rezende. Como a obra de Clotilde Tavares dialoga com várias narrativas da tradição popular e erudita, estimulou-se, ao longo do experimento, a percepção destes diálogos, aspecto enriquecedor da leitura. A vivência com o folheto de cordel, cuja leitura foi realizada por um poeta popular, foi um momento forte da pesquisa no que se refere ao envolvimento dos colaboradores, conforme foi registrado e discutido no decorrer do artigo.
\end{abstract}

Palavras-chave: Romance. Educação de Jovens e Adultos. Leitura

\begin{abstract}
In this article, after situating a reading experience with the novel $A$ botija, by Clotilde Tavares, with EJA students, a reflection about the experience with the booklet $O$ romance do Pavão Misterioso, by José Camelo de Melo Rezende, is presented. As the work of Clotilde Tavares dialogues with various narratives of popular and classical tradition, throughout the experiment, the perception of these dialogues - which is an enriching aspect of reading - was encouraged. The relation with the string literature, whose reading was performed by a popular poet, was a strong moment of the research with regard to the involvement of employees, as it is registered and discussed throughout the article.
\end{abstract}

Keywords: Novel. Youth and Adult Education. Reading.

\section{Introdução}

Nas últimas décadas o ensino de literatura, assim como as práticas voltadas a não leitura de textos literários na escola têm se tornado alvo de reflexões no campo dos estudos educacionais. No entanto, na contramão do que ocorre com o ensino da língua que se renova com o auxílio nas novas tecnologias, no ambiente escolar continua à margem das atividades escolares, resistindo "às mudanças e se vê relegada a lugar secundário e sem força na formação das crianças, dos adolescentes e dos jovens" (DALVI, REZENDE, JOVERFALEIROS, 2013, p. 09).

Apesar das melhorias visíveis no atual quadro do ensino de leitura ainda é perceptível que, no sistema educacional da maioria de nossas escolas, prevalece o ensino de literatura pautado no viés historicista dos períodos e gêneros literários, prendendo-se às análises dos autores e suas obras. Neste processo, por vezes, desconsidera-se o papel do leitor, seus horizontes de expectativas e o efeito estético do texto sobre o mesmo. Esta realidade, percebida no Ensino Médio, também está presente na Educação de Jovens e Adultos (EJA) onde a literatura apresentada consiste apenas em fragmentos de textos literários voltados, exclusivamente, ao ensino da gramática normativa e a significações limitadoras.

\footnotetext{
* Mestre em Linguagem e Ensino pela Universidade Federal de Campina Grande - UFCG. Professora da rede pública estadual de ensino do Rio Grande do Norte.E-mail: ananiliameire@ hotmail.com

** Doutora em Literatura Brasileira pela Universidade Federa da Paraíba - UFPB. Professora adjunta da Universidade federal de Campina Grande - UFCG. Campus de Campina Grande. E-mail: tavares.cg@hotmail.com
} 
A literatura tem o poder de encantar, seduzir, transgredir, instigar o leitor à percepção crítica do mundo a sua volta através da identificação e conhecimento de si mesmo e dos outros. Nas discussões acerca da leitura literária e da formação de leitores se enfatiza o espaço escolar como privilegiado ao estímulo da leitura. Porém, nossas salas de aula ainda estão distantes de serem espaços de formação leitora.

Salvas as devidas exceções, grande parcela de nossos estudantes continua a ter contato com os livros apenas em função dos processos seletivos, testes ou conteúdos avaliativos cujas respostas às atividades não dão margem a mais que uma interpretação; os textos são utilizados como pretexto ao ensino da gramática normativa ou estão descontextualizados a vivência dos alunos. Assim, o que deveria ser uma experiência lúdica e enriquecedora se transforma em algo maçante.

Em Literatura em perigo (2009, p. 8), Todorov aponta que a literatura corre o risco de não mais "participar da formação cultural do indivíduo", considerando a forma disciplinar como o texto literário tem sido ofertado aos jovens, desde a infância à universidade. Estes não mantêm contato regular com a literatura, apenas a crítica ou a história literária, fazendo com que sua leitura se torne um tormento aos que frequentam os bancos escolares e o prazer de ler seja anulado. Diante deste fato, os jovens em formação leitora têm demonstrado gradativo desinteresse pela literatura trabalhada nas salas de aula.

Assim, o perigo que cerca a literatura é o desta perder seu poder de participar na construção cultural, afetiva e intelectual dos indivíduos e formar não só leitores, mas cidadãos, conhecedores de si mesmos e dos Outros. Faz-se necessário que, no processo educacional, o texto e a leitura literária passem a ocupar o centro e "não a periferia" (cf. TODOROV, 2009, p. 11).

Mediante estas constatações, apresentaremos neste artigo um recorte da experiência com a leitura literária, desenvolvida em formato de oficina, em duas turmas da Educação de Jovens e Adultos (EJA), no Centro de Educação de Jovens e Adultos (CEJA), na cidade de Currais Novos- RN entre os meses de outubro a dezembro de $2013^{1}$. Esta intervenção consistia em suscitar reflexões acerca da recepção do romance pelo público leitor da EJA, percebendo como, a partir da obra A Botija (2003) de Clotilde Tavares, contribuiríamos com a formação leitora dos discentes desta modalidade de ensino. Buscou-se uma experiência de leitura significativa com este gênero literário ainda pouco utilizado em sala de aula em decorrência da escassez de tempo para realizar esta tarefa, optando-se, geralmente, por textos curtos como o conto, a crônica, a fábula, entre outros.

Realizamos o experimento em uma escola do sistema público de ensino em razão deste ser responsável pela educação formal da maior parte da população brasileira e o planejamento anual destas instituições ser flexível a modificações, permitindo que a Oficina de Leitura acontecesse em um momento decisivo do ano letivo de 2013. Dentre os níveis educacionais, selecionamos a EJA por três razões: é uma modalidade de ensino diferenciada, havendo poucas pesquisas direcionadas a ela, ao menos sob o enfoque a que se destina este trabalho; sua matriz curricular é trabalhada em metade do tempo destinado à educação regular, restando-lhe ainda menos espaço ao trabalho com textos como o romance; os estudantes que a frequentam pouco vivenciaram a experiência literária em sala de aula, seja por terem se afastado dos bancos escolares por longo período de tempo ou pelas sucessivas desistências, evasões ou reprovações.

\footnotetext{
${ }^{1} \mathrm{O}$ relato completo da experiência e estratégias de leitura utilizadas está disponível na dissertação "Tecendo leitores e leituras: A Botija em sala de aula", defendida por Ananília Meire Estevão da Silva no Programa de Pós-graduação em Linguagem e Ensino (POSLE), na Universidade Federal de Campina Grande (UFCG) em setembro de 2014.
} 


\section{Uma botija... inúmeras leituras}

A Botija narra a história do seleiro Pedro Firmo. Homem que aos cinquenta anos de idade "nunca tinha se casado nem tinha filhos [e que] talvez o fato de não saber da sua origem imprimira em sua personalidade a marca da solidão" (TAVARES, 2003, p. 13). Pedro Firmo mora na fazenda Porteira Roxa, interior de Minas Gerais. Há anos sonhava com uma botija enterrada na 'Tabacaria Flor de Maio' no centro da cidade do Recife. Certo dia, ele decide ir em busca do tesouro que lhe estava predestinado. No caminho até o Recife vive inúmeras aventuras e encontra personagens que o auxiliam em sua jornada como o Feiticeiro, a cigana Gipsy e o dono da tabacaria que, assim como ele, também sonha com um tesouro enterrado em uma fazenda mineira.

A obra apresenta em sua gênese a união de três narrativas populares, sendo dois contos e um romance, a saber: a história de Pedro Firmo cuja busca pela realização de seu sonho é temática comumente encontrada na literatura, a exemplo da "História dos dois que sonharam", pertencente As mil e uma noites e recontado por Jorge Luis Borges em História universal da infâmia e outras histórias (1975); Eulália e seu Pai Feiticeiro também conhecido como "A filha do Diabo" e o Romance d'O Pavão Misterioso (2000). As narrativas são entrelaçadas de forma poética, constituindo os s núcleos temáticos centrais. As duas últimas histórias citadas têm seus enredos narrados pela personagem Gipsy, como elemento narrativo que auxilia Pedro Firmo na busca pela botija encantada presente em seus sonhos. Pelo modo como a obra está estruturada, apresentam-se características de uma apropriação de outros textos no corpo narrativo, mostrando-se ao leitor como a junção de contos e histórias narrados e entrelaçados. Assim, percebemos vozes várias na construção do texto por meio de marcas estruturais, formais e estilísticas, que conferem ao romance um caráter polifônico, caracterizado pela justaposição de vozes marcadas no imaginário do grupo social e cultural que se apresenta (cf. BAKHTIN, 1999).

Nascida das narrativas populares, a obra de Clotilde Tavares não apresenta apenas os caracteres romanescos, visto que é a junção de vários estilos literários e, portanto, um texto aberto, polifônico. Para Bakhtin (2003), o romance é um gênero em devir, eternamente inconcluso. A partir do entendimento de que o discurso e o sistema ideológico são inseparáveis, Bakhtin revoluciona a teoria do romance ao elaborar os conceitos de dialogismo e polifonia, termos que exprimem a interação de vozes nos diálogos estabelecidos no universo social e representados no romance. Para este estudioso o $e u$ só existe em interação com o outro ou com os outros, porque "ser significa ser para o outro e, através dele, para si mesmo" (BAKHTIN, 2003, p. 195 - 205). Deste modo, o dialogismo consiste no modo de elaboração narrativa do romance polifônico no qual circulam várias vozes.

Julia Kristeva em $O$ texto do romance (1984) acrescenta que o princípio do romance, assim como as transformações que o caracterizam historicamente ocorrem em um "espaço intertextual". Desse modo, a teoria da intertextualidade proposta por Kristeva aponta para a realidade do texto como resultado da relação estabelecida entre este e outros textos e uma forma de leitura não linear, sugerindo ao leitor dois caminhos: prosseguir a leitura sem estabelecer determinadas relações, pois as desconhece ou retorna ao texto de origem em busca de elementos que auxiliem a compreensão do romance. Ambos os caminhos foram traçados pelos participantes da oficina de leitura realizada como veremos adiante. Enquanto alguns alunos associavam elementos da obra com suas experiências pessoais outros não foram capazes de estabelecer tais pontes, pois não possuíam repertório leitor suficiente.

\footnotetext{
${ }^{2}$ Versões do conto "A filha do Diabo" podem ser encontradas na obra Armadilhas da memória: conto e poesia popular (1991) de Jerusa Pires Ferreira.
} 
A Botija, enquanto texto híbrido sofre influência da literatura oral, não só por abarcar elementos pertencentes a esta literatura - como os versos cordelísticos em sextilhas que compõem algumas falas da personagem Gipsy que estão, comumente, intercalados à prosa das histórias que narra, como a história do Pavão Misterioso que é recontado em prosa. Outrossim, pela linguagem próxima do falar popular que lhe é empregada.

O romance selecionado dialoga com um vasto universo textual, passeando pela tradição popular aos textos canônicos, do gênero bíblico ao infantil. Pontuaremos alguns deles como sugestões para uma proposta metodológica possível a ser empregada no contexto escolar, visando a ampliação de referências de leitura e a oferta de elementos de reflexão a retomada que faz dos seguintes textos:

1) Conto "O príncipe pequeno" que compõe a obra Histórias de Velha Totônia (2001)

2) "História dos dois que sonharam", narrativa pertencente As mil e uma noites.

3) A história de Elias e o carro de fogo - narrativa bíblica na qual o elemento maravilhoso e/ou fantástico se faz presente, assim como na obra de Clotilde Tavares.

4) Os contos de fadas "Rapunzel" e "Branca de Neve" - Transcrito pelos irmãos Jacod e Wilhelm Grimm.

5) "Os doze trabalhos de Hércules" - o diálogo com esta narrativa mitológica grega, se estabelece a partir das tarefas impossíveis propostas pelo Feiticeiro a Flaviano, cumpri-las seria a única forma para salvar sua vida.

Os textos acima citados foram selecionados por serem de fácil aquisição e por possibilitar ao aluno a leitura do texto original e a recriação realizada por Clotilde, comparálos, perceber e discutir pontos de aproximação e distanciamento entre as narrativas, que aspectos foram enfatizados e que efeito acarretou dadas escolhas.

Como se observa, A botija é o espaço em que diferentes narrativas populares cruzamse, interrelacionam-se, imbricam-se, fazendo-se necessário desfazer o jogo ficcional para perceber a sua diversidade, trazendo-nos assim a ideia de palimpsesto, de diálogo, provocando o enriquecimento estético da obra.

O romance A Botija (2003) foi selecionado para esta vivência literária por quatro aspectos: 1) ser um gênero literário cuja leitura integral em sala de aula ainda se faz ausente; 2) ser elaborado sob os pilares das narrativas populares e da ludicidade provocada pelas brincadeiras infantis, cantigas de rodas, cantigas de ninar, entre outros elementos, dialogando com os diferentes gêneros; 3) por sua proximidade com o universo imaginário do leitor possibilitando um contato efetivo com o texto a partir da experiência estética, incentivando a prática leitora e primando pelo letramento literário; 4) ser uma obra significativa no espaço literário potiguar ainda pouco conhecida do público estudantil e de grande parte dos educadores do Rio Grande do Norte.

\section{A oficina de leitura}

A oficina de leitura "Conto estas histórias como me contaram. Quer ouvir?: leituras do popular" ocorreu em duas etapas: a observação participativa e os encontros para leitura dos capítulos do romance de Clotilde Tavares.

$\mathrm{Na}$ primeira etapa foram observadas cinquenta horas/aula nas turmas de EJA do Ensino Fundamental e do Ensino Médio, durante as quais foram recolhidas informações relacionadas ao perfil das turmas, às atividades de leitura literária em sala de aula, perceber as dificuldades em realizar tais tarefas e aquelas apresentadas pelos participantes quanto à leitura e compreensão, o trabalho de mediação da professora.

Os dados coletados apresentaram certa discrepância no tocante às atividades referentes à leitura realizadas em ambas as turmas, sendo mais frequentes na turma do Ensino 
Fundamental. Tal fato pode ser motivado por como: os discentes do Ensino Fundamental eram mais dispersos e raros realizavam as tarefas de leitura propostas pela professora. Assim, sempre que podia a docente realizava a leitura dos textos distribuídos ou propostos pelo Livro Didático, junto com os alunos, em sala ou na biblioteca. Já no Ensino Médio, o ritmo de leitura era diferenciado, possivelmente, pela escassez de tempo para realizar as leituras a serem discutidas em grupo ou para vencer o extenso conteúdo gramatical do Ensino Médio e a seção de literatura, optando-se pelo primeiro por ser melhor aproveitado, segundo a ótica discente, no mercado de trabalho.

Apesar das divergências, percebemos pontos semelhantes nas referidas turmas, a saber: a frequência irregular dos alunos às aulas; há livros didáticos, mas estes permanecem na escola e, quando necessários, são retirados como empréstimo da biblioteca; o hábito da leitura literária não é comum entre os estudantes que, em sua maioria, trabalham nos horários paralelos aos das aulas; gostam de ouvir alguém contar ou ler para eles mais do que ler em voz alta, portanto, estão mais disponíveis para ouvir do que para ler; alunos desatentos; alguns discentes apresentavam dificuldades em interpretar e compreender o que havia sido lido ou de recordar conteúdos. Assim, a professora sempre iniciava a aula revisando o encontro anterior, pedindo para que exemplificassem ou comentassem a tarefa realizada anteriormente.

As informações colhidas nesta etapa foram significativas e auxiliaram na execução do projeto, na reformulação de alguns pontos do planejamento inicial, considerando o objetivo de fazer com que o contato das turmas com o romance fosse algo prazeroso, semeando-lhes o gosto pela leitura.

A segunda etapa da experiência foi dividida em sete encontros e o romance lido integralmente em classe com e pelos alunos, a partir de estratégias que privilegiaram o diálogo entre a obra escrita por Clotilde Tavares e os textos-fonte nos quais a autora dialoga. A narrativa foi trabalhada no formato de telenovela, isto é, com a leitura diária em capítulos estratégicos na intenção de instigar a curiosidade para o próximo encontro, favorecendo assim, o campo da formação leitora. Neste momento da experiência de leitura, serviu-nos como instrumento para coleta de dados o Mapa de Leitura, as atividades de produção textual e o questionário aplicado aos alunos e à professora colaboradora. É, pois a partir dos dados coletados que agora relatamos e analisamos os instantes que fizeram estes encontros. Embora as turmas fossem distintas, as estratégias de leitura realizadas em ambas foram semelhantes e as informações contidas neste trabalho encontram-se mescladas à realidade das turmas envolvidas na oficina.

Já no início da oficina, ao expormos o propósito de desenvolver uma atividade relacionada à leitura e enfatizarmos a literatura potiguar os discentes afirmaram que ainda há muito a conhecer na poesia e na prosa do estado, citando a história literária de Currais Novos e do Seridó, berço de José Bezerra Gomes e de tantos escritores e poetas líricos e populares como Celestino Alves, Luiz Carlos Guimarães, Suetônia Batista, Moacy Cirne, Amazan, Sebastião Silva e os repentistas José Omar, José Lúcio, Geraldo Brito, Carlos Alberto, dentre outros.

Após a distribuição do material que seria utilizado durante a experiência distribuímos o questionário com os discentes. Dos trinta e quatro matriculados nas turmas acompanhadas, vinte e dois responderam ao questionário proposto.

Durante este momento, os alunos expuseram de modo oral e escrito suas dificuldades quanto à leitura e testemunharam acerca de sua formação leitora. Apontaremos a seguir alguns dos dados coletados:

- a maioria dos alunos $(86,3 \%)$ se considera um leitor e aponta que, mesmo não gostando de ler tudo o que lhes é oferecido pela escola; Ou ainda, por ser hábito adquirido na 
infância, para "aprender mais" (aluno $\mathrm{ML}^{3} 0^{3}$ ), ter acesso a informações e notícias momentâneas ou aprimorar conhecimentos linguísticos e ortográficos, como é possível observar na fala da aluna MA3 quando afirma "gosto de ler, pois além de ser um hábito me ajuda na ortografia e no conhecimento";

•embora o prazer apareça relacionado à leitura, este sentimento está relacionado a textos jornalísticos, de revistas e outros, não necessariamente ao texto literário;

- a partir da fala dos discentes pontuamos dois fatores que corroboram para o "não gostar" de ler no ambiente escolar: a imposição realizada pela escola através de textos descontextualizados que não satisfazem os horizontes de expectativas de seus leitores, relacionando o ato de ler ao verbo "dever", atividade mecânica medida pelo número de páginas vencidas (JOUVE, 2013; PENNAC, 2011); a não realização de atividades voltadas à formação e incentivo do hábito leitor.

-a leitura é importante para todos, mas apenas 18,1\% afirmaram não frequentar espaços de leitura por não terem afinidade com os mesmos ou não gostarem de ler, assim as informações lhes chegam comumente através dos meios de comunicação audiovisuais como a $\mathrm{TV}$, o rádio, a internet. •quando conectados à internet suas fontes de leitura mais citadas foram jornais, revistas e textos diversos como mangá, autoajuda, suspense, tirinhas e charges;

- a escola é citada como o ambiente em que grande parcela do público colaborador tem acesso aos textos literários;

-a família, o trabalho e a escola são apontados como responsáveis pelo interesse leitor dos sujeitos.

$\mathrm{O}$ ato de ler ainda é compreendido pela maioria como o reconhecimento ou a decodificação dos signos linguísticos. Porém, o significado de ler e de leitura vai além deste conceito. Apreender e interagir, eis as palavras-chave. Ler não é apenas decodificar e distinguir, mas também compreender e interpretar. É, pois um processo de interação entre o leitor e o texto como nos aponta Iser (1979), no qual além de compreender são atribuídos sentidos a partir das experiências vivenciadas, "uma operação de percepção e de identificação" como afirma Jouve (2002, p. 17).

Para Jauss (1979, p. 8), a recepção dos textos literários ou de outras obras de arte não é um objeto de consumo passivo, mas uma atividade que envolve um efeito estético, pois está "pendente da aprovação ou da recusa".

No contexto escolar, a organização de grupos de leitores, oficinas ou encontros quinzenais durante um dos horários da aula para relato e discussão dos textos seria o passo inicial para desmistificar a sala de aula como o lugar em que se lê por obrigação. Poderia, por outro lado, constituir uma significativa experiência literária onde é possível vivenciar o deleite nas páginas de um livro. Compartilhar experiências de leitura enriquece nosso repertório interpretativo a partir dos desafios simbólicos que propõe e das significações que as obras têm para os outros, proporcionando um diálogo permanente entre leitores/ textos, a troca de indicações de leitura e a ampliação os hábitos leitores.

Teresa Colomer (2007, p.106) aponta a leitura como uma forma de aprendizado social e afetivo, sendo a "leitura compartilhada a base da formação de leitores". Ao compartilhar suas leituras, compartilha-se também "o entusiasmo, a construção do significado e as conexões que os livros estabelecem entre eles" (COLOMER, 2007, p. 107). Para que tal experiência seja exitosa, cabe também ao professor planejar, escolher o corpus, incentivar a leitura integral das obras e inter-relacionar as atividades de leitura e escrita.

Conforme nos aponta Pinheiro (2002) é a pesquisa acerca dos interesses, isto é, dos possíveis horizontes de expectativas dos estudantes para que, partindo deste ponto, possam ser

\footnotetext{
${ }^{3}$ Os discentes serão identificados pelas letras $\mathrm{F}$ ou M, para aqueles que frequentam o Ensino Fundamental ou Médio, respectivamente, seguidas pela primeira letra do nome e um número ordinal.
} 
oferecidas obras que sejam mais facilmente apreendidas e, sucessivamente tenham seu grau de dificuldade modificado.

Vale salientar que faz-se necessário compreender que o trabalho com a leitura, de maneira geral, não é atribuição apenas dos professores de Língua Portuguesa, mas da comunidade escolar, pois a interpretação e compreensão dos enunciados são necessárias em todas as áreas do conhecimento.

\section{$4 \mathrm{Um}$ dos caminhos percorridos}

Considerado o perfil das turmas traçado a partir dos dados coletados na primeira etapa da experiência, mediamos os encontros seguintes buscando atender ao horizonte de expectativas dos participantes e ampliar seu repertório de leitura, atentando para o leitor como coautor da obra e os textos-fonte do referido romance.

Outros seis encontros foram realizados, porém, o que será descrito aqui caracterizase pelo envolvimento dos participantes seduzidos pela leitura de $O$ romance do Pavão Misterioso de José Camelo de Melo Rezende.

As estratégias de leitura elaboradas estão embasadas nos estudos de Cosson (2011, p. 40 - 47) quando este afirma que a leitura deve ser compreendida como um processo linear a partir de três etapas: antecipação, decifração e interpretação. A antecipação consiste nas operações realizadas pelo leitor antes de adentrar no texto, sendo relevantes os objetivos da leitura e os elementos que materializam o texto como capa do livro, título, número de páginas, entre outros. Na decifração entramos no texto por meio das letras e palavras e quanto maior for nossa familiaridade com elas melhor será este processo. A etapa de interpretação diz respeito às "relações estabelecidas pelo leitor quando processa o texto". Esta etapa está centrada nas inferências que o leitor realiza ao entrelaçar as palavras com o conhecimento que tem do mundo, negociando os sentidos do texto em um "diálogo que envolve autor, leitor e comunidade". Desse modo, os pressupostos para que se desenvolva um letramento literário, de fato significativo, aponta que o centro deverá ser sempre a experiência com o texto literário. Neste caso, tornam-se importantes tanto a leitura quanto as respostas que construímos para ela na interação texto/leitor.

\section{Tecendo as histórias}

Neste momento da oficina, mais especificamente o quinto encontro, apresentamos aos participantes a terceira narrativa que compõe a obra de Clotilde Tavares, $O$ romance do Pavão Misterioso narrado a partir do seu texto-fonte, o folheto de cordel.

Constatamos anteriormente que a leitura começava a se tornar cansativa para os alunos. Por mais que diversificássemos as estratégias o público leitor não estava habituado a textos e a atividades de leitura extensos. Portanto, decidimos:

1 - convidar o poeta Claudson Faustino 4 para realizar junto aos discentes a leitura do folheto de José Camelo de Melo Rezende. Este romance em cordel corresponde a história de amor verdadeiro que a cigana Gipsy conta para Pedro Firmo, auxiliando-o a seguir viagem na busca por sua botija.

\footnotetext{
${ }^{4} \mathrm{O}$ poeta e escritor Claudson Faustino é natural de Currais Novos e faz parte do grupo Cordel do Pau Quebrado que realiza apresentações performáticas e leituras de cordel em eventos e escolas do estado. Para maiores informações sobre o grupo acessar < $\underline{\text { http://cordelpauquebrado.blogspot.com.br/> }}$.
} 
2 - por ser o trecho mais extenso da narrativa, equivalendo a dezessete de seus trinta capítulos, optou-se pela leitura d'O romance do pavão misterioso, texto-fonte onde Clotilde Tavares buscou referências para a história contada. Tal fato insere nas aulas outro gênero literário, o cordel, pouco lido em sala de aula.

Segundo Marinho e Pinheiro (2012), a "experiência com a poesia oral está presente em toda a comunidade", portanto não será raro encontrar entre os que frequentam a escola ou entre aqueles com quem estes mantêm contato, alguém que aprecie ou mesmo pratique a literatura popular. A entrega dos folhetos colaborou para que o aluno (re)descobrisse, a partir da leitura oral, esta forma literária

Para a realização deste encontro, fixamos xilogravuras retiradas d'A Botija e cujas imagens narravam a história que seria apresentada na sequência. A presença das xilogravuras neste encontro e no anterior dialogaram com a cultura popular já existente na obra e agora se apresentava aos alunos por meio da literatura de cordel, ampliando o horizonte de expectativas destes no que concerne à criação dos personagens, pois os visualizam através das imagens.

Os folhetos de cordel cujas leituras seriam efetuadas no encontro, foram entregues acompanhados de uma moeda de chocolate. Expomos aos alunos que o encontro com o tesouro estava próximo e mais uma moeda havia sido encontrada. Inferimos se os presentes já haviam ouvido ou lido em cordel e alguns afirmaram que sim, mas não recordavam a história.

Tornou-se comum recapitularmos brevemente o que havia sido lido e/ou contado até então para que continuássemos acompanhando a saga de Pedro Firmo que MJ8 comparou à "saga do vaqueiro", pois para ele as dificuldades enfrentadas pelo personagem para encontrar sua botija assemelhavam-se àquelas vividas pelo nordestino, representado em sua colocação pelo estereótipo do vaqueiro. Para realizarmos esta retomada empregávamos a estratégia de perguntas e respostas acerca dos personagens e detalhes da narrativa. Percebemos durante estas atividades que os estudantes acompanhavam atentos os acontecimentos narrativos.

Em seguida, convidamos Claudson Faustino para contar a história de amor verdadeiro. A presença do poeta, já conhecido por alguns estudantes, foi positivamente recebida. Ao ser iniciada a leitura do folheto pelo poeta fez-se um enorme silêncio na sala quebrado apenas pelo riso e algumas expressões, em determinados momentos da narrativa, que tentaremos transpor abaixo, conscientes de que as palavras aqui transpostas não serão capazes de repassar ao leitor as experiências e a recepção vivenciadas neste momento.

Mesmo não utilizando performances corporais para a contação, o poeta a faz na sonoridade ao atribuir vozes e ritmos de fala específicos para os personagens, fazendo o riso transparecer entre os alunos em momentos como os exemplificados abaixo:

-João Batista diz a Evangelista que lhe trouxe um retrato da condessa Creuza: "FP6 Eita, danado”!; “MA1 - Vixi, Nossa Senhora!'”;

-na terceira viagem do pavão Creuza avisa ao pai que havia seguido seu plano e passado a banha amarela em Evangelista: "MAl - Viiixi!!", reprovando a ação da moça, seguido de um "ah, meu Deus!" (MA1) quando o Conde ordena a prisão do personagem;

-Creuza chora ao se arrepender da traição contra Evangelista: "MA1 - Coitada!" e afirma que desejaria rever o rapaz para pedir-lhe perdão mesmo que depois morresse na mesma hora: "MR5 - "Viixi!! (risos)";

- Creuza, após marcar evangelista com a banha amarela perde a esperança de livrar-se da prisão imposta pelo pai: "MAI - "Bem feito, otária. Se fosse eu já tinha me jogado em cima dele. (risos)";

•Evangelista regressa ao quarto de Creuza na última viagem do pavão: “MJ8 - "Vão fugir!" e ouvem-se risos debochados ao Conde; 
-quando é narrado que Evangelista engana os guardas que o vieram prender e foge voando no pavão ouvem-se risos e assovios a concordar com a esperteza e sagacidade do personagem, enganando seus algozes.

Ansiosa e atenta à narrativa, assim como os outros colaboradores presentes, MA1 inicia a leitura de uma das últimas estrofes "Creuza disse..." e o poeta Claudson Faustino continua a leitura do ponto em que ela havia parado, envolvendo ainda mais a aluna na leitura e, por não "cortar-lhe" a voz, reiniciando a estrofe, a torna também sua narradora. À medida que o poeta lê as últimas estrofes ela o acompanha em voz alta e ao fazê-lo envolve-se com o texto, projetando-se nele como se fosse sua participante.

Ao concluir a narração ouvem-se aplausos, assovios e a declaração de MA1 "linnndo!!" e indaga a Claudson "e a música do pavão misterioso. Você sabe cantar?" ao que ele responde " infelizmente não" e despede-se do público. A aluna MA1 em sua fala dirigida ao poeta realiza o processo intertextual entre o folheto de José Camelo de Melo Rezende e a canção "Pavão Misterioso" interpretada por Ednardo e tema da novela e série televisiva Saramandaia, ambas exibidas pela Rede Globo de Televisão, que estava em exibição no período em que foi realizada a oficina.

Durante o momento de contação da história observamos algumas outras reações dos discentes. O aluno FL4 estava inicialmente atento ao registro que realizava com o celular, mas em dado momento o que ouvia e via tornou-se tão mais interessante que ele deixou a gravação de lado e passou a acompanhar pelo folheto. A maioria dos presentes ficaram encantados no começo com as expressões vocalizadas de Claudson, a ponto de sequer abrirem os folhetos, acompanhando a história com o olhar fixo no seu recitar. Porém, minutos depois, envolvidos pela leitura e sua sonoridade, começaram a abrir os folhetos e acompanhá-la, balbuciando-a no ritmo em que era recitada como se o texto os atraísse, convidando-os a serem também seus coadjuvantes.

O colaborador FN12 que havia afirmado minutos antes, no corredor da escola, que não gostava de ler abriu o folheto, acompanhou a narrativa balbuciando-a e rindo das passagens que considerava engraçadas. Os discentes FJ3 e MW6 que durante as aulas estavam sempre acompanhados de seus respectivos fones de ouvindo os esqueceram por instantes e acompanharam a narrativa pelo folheto. Já MW6 denotava estar apreciando a leitura, pois estava sempre com um ar de riso no rosto enquanto que FJ3 começou a acompanhar pelo folheto quando Claudson passou a narrar a viagem de Evangelista à Grécia em busca de Creuza, demonstrando que neste momento suas expectativas de leitura eram atingidas. Estes momentos de recepção do texto protagonizados pelos estudantes revelam que o gênero ou formato textual quando aliados às estratégias de leitura adequadas ao público leitor podem deflagrar a experiência estética, pois a leitura só se efetiva quanto o texto significa para o seu leitor, satisfazendo suas expectativas quanto aos temas ou reações que o texto possa suscitar.

O cordel, em sua trajetória histórica tem sido fonte de informação, de lazer, de crítica social, de reinvindicações, de alfabetização e de incentivo ao ensino de Literatura. Ao abordar de forma humorada e, não tão direta, aspectos sociais presentes no cotidiano, os folhetos de cordel favorecem a interação entre o texto e seus leitores (cf. MARINHO E PINHEIRO, 2012). Como pode ser vivenciado nas expressões orais e gestuais dos discentes durante a declamação realizada.

Após a conclusão da leitura do folheto, paramos diante dos alunos por alguns segundos, observando-os e estes faziam um profundo silêncio, quebrado por MJ8 que exclama "um minuto de silêncio pela leitura boa". Os colaboradores pareciam encantados pela história, com o momento de ludicidade que vivenciavam a espera de uma continuação que ocorreria na imaginação do leitor/ ouvinte.

Percebemos que alguns colaboradores seguiram o pacto de leitura (JOUVE, 2002, p. 67) proposto pelo texto, seguindo as pistas que lhes eram sugeridas de forma explícita ou 
implícita, orientando sua recepção, a exemplo do "era uma vez" no início do romance, convidando à ficcionalidade. Outros participantes continuam a (re)formular hipóteses tomando como parâmetro o universo não fictício.

Ao final do encontro indagamos acerca da história que acabávamos de ouvir, e, entusiasmado MJ8 exclama: "professora, eu estou gostando muito mais! [...] Falando sério é bom demais", demonstrando a satisfação que o texto lhe proporcionou. A estudante MA1 saiu da sala envolvida pela ficção, cantarolando o refrão da canção de Ednardo: "Pavão Misterioso, pássaro formoso, tudo é mistério nesse teu voar...". Esta ação nos aponta que sua identificação com a leitura ultrapassou os limites do texto literário, permitindo-lhe perceber que este último não é isolado, pois se correlaciona a outro discurso presente na música, estabelecendo um movimento dialógico entre ambos.

Reações advindas dos estudantes como retirar os fones de ouvido e ultrapassar as próprias dificuldades leitoras para acompanhar a narração em cordel seguida de expressões faciais, orais e do riso nos demonstrou que o cordel, a partir dos elementos que lhe são característicos como a musicalidades, diversidade de temas e a presença do humor, exerceu sobre os discentes um encantamento que os fez direcionar sua atenção ao romance contado por Claudson Faustino.

\section{Refazendo a caminhada}

Durante a Oficina de Leitura "Conto estas histórias como me contaram. Quer ouvir?: leituras do popular" solicitamos as turmas participantes que registrassem no Mapa de Leitura as impressões, dúvidas, sentimentos, hipóteses acerca do romance A Botija. O Diário de Leitura, conforme Machado et al (2007, p. 109), é um texto que vai sendo construído pelo leitor enquanto realiza a leitura de um outro, seja ele oral ou escrito, objetivando estabelecer uma conversa reflexiva com o autor acerca do que foi lido, desenvolvendo atos de linguagem como manifestar a compreensão ou não acerca do que nos diz o interlocutor, sintetizar a compreensão textual, concordar ou discordar da posição adotada pelo texto, argumentar, avaliar, relacionar o que é dito a experiências pessoais ou a outros textos ouvidos ou lidos, entre outros pontos.

Conforme Machado et al (2007, p. 65 - 68), uma boa leitura vai além do que está expresso no texto ou dos posicionamentos diante de um tema abordado. A identificação com o personagem, aspectos culturais, sociais e intelectuais evidenciam as diversas formas pelas quais um só texto pode ser avaliado diferentemente por seus leitores. Tomando por base tais afirmações, analisamos os registros em alguns dos Mapas de Leitura que nos foram entregues acerca das sensações provocadas pela leitura do cordel em sala de aula. Abaixo compartilhamos.

Em seu Mapa de Leitura FL4 registra passagens que vivenciou durante os encontros como a vivência com o texto literário quando Claudson Faustino declamou o romance $\mathrm{d} O$ Pavão Misterioso em classe, declarando que o momento "foi massa" e ressaltando as expressões orais e corporais realizadas pelo artista como um dos elementos essenciais à sua experiência estética com o cordel.

A colaboradora MR5 também aponta como um momento mágico a leitura do folheto como um dos instantes com os quais mais vivenciou o texto durante as aulas, ressaltando a importância da performance de leitura, não somente por meio de textos em prosa, mas também em versos. Coloca temas como o amor, a determinação, a coragem presentes no romance como "lições de vida", ensinando-a a perceber o universo que a envolve e, por fim, cita a oportunidade de conhecer a autora potiguar Clotilde Tavares como "uma mulher 
inteligente e antenada" a ponto de prender o leitor às páginas de seu livro, bem como a importância do incentivo à leitura realizada em sala de aula.

\section{Considerações finais}

Neste espaço de discussão, considerou-se a escola como ambiente propício e interdisciplinar à formação de cidadãos autônomos, críticos e participativos. Compreende que formar leitores constitui o grande desafio a ser alcançado pela educação brasileira uma vez que o texto literário e as atividades mediadoras da leitura ainda se encontram ausentes da sala de aula.

Nossa pesquisa enveredou pelo caminho da observação e da reflexão acerca da recepção do romance pelo público da Educação de Jovens e Adultos (EJA) a partir da realização da Oficina de Leitura e da leitura de A Botija (2003) de Clotilde Tavares. Durante a vivência com o referido gênero, ainda pouco presente no ambiente escolar, assim como a poesia e a cultura popular, percebemos como este, aliado a estratégias mediadoras de leitura pode contribuir com a formação leitora dos discentes e possibilitar uma experiência de leitura significativa.

Para a leitura do romance seguimos alguns passos que consideramos primordiais para o contato e aceitação dos estudantes frente à obra. Quando vamos a uma livraria, biblioteca ou banca de revistas e escolhemos um livro ou revista nosso primeiro contato ocorre com a materialidade do mesmo: as cores, formato, imagens, títulos. Assim, o primeiro passo realizado para iniciarmos a leitura dos capítulos em sala de aula foram as análises dos elementos extratextuais como título, capa, ilustrações que nos permitiram traçar hipóteses sobre a obra, temas que seriam abordados, personagens, espaço da narrativa com o intuito de despertar o desejo e interesse dos colaboradores em lê-lo.

Em um de nossos encontros, mais especificamente aquele no qual realizamos a leitura do Romance do pavão misterioso, texto de José Camelo de Melo Rezende, percebeu-se que, por alguns instantes, os estudantes que ali estavam participando da leitura do folheto de cordel reencontraram o prazer da leitura e vivenciaram uma experiência estética ao adentrarem no texto por meio da narração de Claudson Faustino, imaginando e vivenciando junto aos personagens Creuza e Evangelista as aventuras a bordo do pavão que cruzava os céus nas noites gregas. Neste momento da oficina de leitura, a imaginação seduziu o leitor do romance e o prazer se deu de modo gratuito como deve ser toda leitura. O envolvimento dos colaboradores neste momento de contação foi tal que a identificação com a leitura possibilitou a percepção do texto literário não como elemento isolado, mas correlacionado, interligado a outros discursos e gêneros em um movimento de constante dialogismo.

Em um processo de leitura, o bom leitor não é aquele que apenas decifra os códigos linguísticos, compreendendo o que está expresso no texto, mas o que se transforma em agente comunicativo e criativo, estabelecendo relações entre o que é lido, suas experiências pessoais e outras leituras como filmes, música, pinturas e obras culturais aos quais tem acesso.

Ao propormos este trabalho com a obra de Clotilde Tavares em sala de aula abordamos não somente o gênero romance, mas também o conto e a poesia em forma de cordel, tendo em vista que sua obra está embasada nestes gêneros, como mostrado no decorrer da pesquisa. Os textos com os quais $A$ botija mantém comunicação, diálogo, permitem o navegar por obras literárias que vão da literatura popular ao cânone universal, dando continuidade à formação leitora do público discente. 


\section{Referências}

BAKHTIN, M. A cultura popular na idade média e no renascimento: o contexto de François Rabelais. 4. ed. São Paulo: Hucitec; Brasília: Editora da Universidade de Brasília, 1999.

. Estética da criação verbal. 4. ed. São Paulo: Martins Fontes, 2003. (Coleção Biblioteca Universal)

COLOMER, T. Andar entre livros: a leitura literária na escola. Trad. Laura Sandroni. São Paulo: Global, 2007.

COSSON, R. Letramento literário: teoria e prática. 2. ed. São Paulo: Contexto, 2011.

DALVI, M. A.; REZENDE, N. L.; JOVER-FALEIROS, R. (Orgs.). Leitura literária na escola. São Paulo: 2013.

FERREIRA, J. P. Armadilhas da memória: conto e poesia popular. Salvador/ BA: Fundação Casa de Jorge Amado, 1991. (Coleção Casa de Palavra, 8)

ISER, W. A interação do texto com o leitor. In.: JAUSS, Hans Robert et al. A literatura e o leitor: textos de estética da recepção. 2. ed. Seleção, coord. e trad. Luiz Costa Lima. São Paulo: Paz e Terra, 1979. p. 83 - 132.

. $O$ ato da leitura: uma teoria do efeito estético. Trad. Johannes Kretschmer. São Paulo: Editora 34, 1996. p. 48 - 79. (vol. 1)

JAUSS, H. R. A estética da recepção: colocações gerais. In.: JAUSS, Hans Robert et al. A literatura e o leitor: textos de estética da recepção. Seleção, coord. e trad. Luiz Costa Lima. São Paulo: Paz e Terra, 1979. p. 43 - 61.

O prazer estético e as experiências fundamentais da poiesis, aisthesis e katharsis. In.: JAUSS, Hans Robert et al. A literatura e o leitor: textos de estética da recepção. Seleção, coord. e trad. Luiz Costa Lima. São Paulo: Paz e Terra, 1979. p. 63 -82.

JOUVE, V. A leitura. Trad. Brigitte Hervot. São Paulo: UNESP, 2002.

JOVER-FALEIROS, R. Sobre o prazer e o dever de ler: figurações de leitores e modelos de ensino de literatura.In.: DALVI, M. A.; REZENDE, N. L.; JOVER-FALEIROS, R. (Orgs.). Leitura literária na escola. São Paulo: 2013. p. 113 - 134.

KLEIMAN, A. Oficina de leitura: teoria e prática. 15. ed. Campinas, SP: Editora Pontes, 2013.

KRISTEVA, J. O texto do romance. Lisboa: Livros Horizonte, 1984.

MACHADO, A. R; LOUSADA, E.; ABREU-TARDELLI, L. S. Trabalhos de pesquisa: diários de leitura para a revisão bibliográfica. São Paulo: Parábola, 2007.

MARINHO, A. C.; PINHEIRO, H. O cordel no cotidiano escolar. São Paulo: Cortez, 2012. 
PENNAC, D. Como um romance. Trad. Leny Werneck. Porto Alegre, RS: L\&PM; Rio de Janeiro: Rocco, 2011.

PINHEIRO, H. Poesia na sala de aula. 2. ed. João Pessoa: Idéia, 2002.

PINHEIRO, H.; LÚCIO, A. C. M. Cordel na sala de aula. São Paulo: Duas Cidades, 2001. (Coleção Literatura e Ensino; 2).

REGO, J. L. do. Histórias da velha Totônia. 13. ed. Rio de Janeiro: José Olympio, 2001. p. 43 -59 .

REZENDE, J. C. de M. O romance do pavão misterioso. Fortaleza: Academia Brasileira de Cordel/ Tpynanquim Editora, 2000. (Folheto de Cordel)

SILVA, A. M. E. da. Tecendo leitores e leituras: A botija em sala de aula. 2014. Dissertação (Mestrado em Linguagem e Ensino) - Universidade Federal de Campina Grande, Campina Grande, 2014.

TAVARES, C. A botija. São Paulo: Editora 34, 2006.

TAVARES, C. A botija: uma história de amor, encantamento e aventura para todas as idades. Natal: A. S. Editores, 2003. (Coleção Letras Potiguares)

TODOROV, T. A literatura em perigo. Trad. Caio Meira. Rio de Janeiro: DIFEL, 2009.

Recebido em: julho 2014.

Aprovado em: dezembro 2014. 